\title{
Mild Decrease in Renal Function in HIV-Infected Patients on Antiretroviral Therapy: A Neglected Diagnosis
}

\author{
Andréia M. Menezes ${ }^{1}$, Jorge Torelly², Carolina Barbi ${ }^{1}$, Cristiane C. Camargo ${ }^{1}$, Renata P. Moraes1 and Eduardo Sprinz ${ }^{1,2 *}$ \\ ${ }^{1}$ Faculdade de Medicina, Universidade Federal do Rio Grande do Sul, Porto Alegre-RS, Brazil \\ ${ }^{2}$ Hospital de Clínicas de Porto Alegre, Porto Alegre-RS, Brazil
}

\begin{abstract}
Background: Renal impairment is increasingly reported among HIV-Infected patients and has been associated to an increased chance of cardiovascular disease and death. Therefore, early identification of this problem could help to reduce morbidity and mortality among these individuals. The objective of the study was to determine the prevalence and associated factors with mild decrease in renal function of HIV-infected patients on highly-active antiretroviral therapy (HAART) and undetectable viral load in Brazil.
\end{abstract}

Methods: Individuals between 18-70 years of age with time on HAART $\geq 12$ months, viral load $<50$ copies $/ \mathrm{mm}^{3}$, and CD4 $\geq 200 \mathrm{cells} / \mathrm{mm}^{3}$, were consecutively enrolled at the outpatient clinic of Hospital de Clínicas de Porto Alegre, Brazil. Exclusion criteria were chronic kidney disease, pregnancy and known hepatic disease. Renal function was assessed by the Chronic Kidney Disease Epidemiology Collaboration equation. Mild decrease in renal function was defined as an estimated glomerular filtration rate between $89-60 \mathrm{~mL} / \mathrm{min} / 1.73 \mathrm{~m}^{2}$, for a period of at least 3 months.

Results: From the total of 213 enrolled volunteers, 193 were included in the final analysis. The mean age was 41.5 years, 102 were men $(52.6 \%)$, and $156(80.4 \%)$ were euro-descendants. Mild renal decline was diagnosed in $33.5 \%$ of the patients. Every other year of life $(R R=1.05,95 \% \mathrm{Cl} 1.03-1.06, p<0.001)$ and being euro-descendant $(R R=1.94$; $95 \% \mathrm{Cl} 1.07-3.78 ; \mathrm{p}=0.049)$ were associated to mild decreases, whereas high body mass index $(\mathrm{BMI})(\mathrm{RR}=1.04,95 \%$ $\mathrm{Cl} 1.013-1007, \mathrm{p}<0,001)$ was associated to normal function.

Conclusions: Mild decrease in renal function was extremely common and more than expected in our cohort (33.5\%) which deserves further attention while assisting HIV-positive individuals.

Keywords: HIV; AIDS; Renal function; Kidney disease; HAART; CKD-epi; Brazil

\section{Introduction}

Although overall mortality attributable to HIV related complications have declined worldwide, the diagnosis of chronic degenerative disorders and deaths related to non-AIDS diseases have been increased [1-3]. In this scenario, renal disease is relatively common among HIVInfected patients with a still rising number of different entities of kidney problems being reported [4-8]. Many guidelines recommend screening for factors associated to renal disease at the time of HIV diagnosis and regularly thereafter [9-11].

According to the literature, the overall frequency of any renal disease is around $35 \%$ in HIV population $[5,12,13]$, and chronic kidney disease (CKD) prevalence varies from $4.0 \%$ to $8.4 \%[6,7,12,14,15]$. Decreased renal function in HIV population has been associated with increased mortality and worse outcomes $[1,5,16,17]$. CKD is an established factor of cardiovascular disease in general population. Knowing that HIVpositive individuals are at an increased risk for cardiovascular events, the presence of CKD could further worse these risks, as some studies have already suggested [18-21].

Nevertheless, intervening in early stages of renal disease could lead to improvement in short and long term outcomes, even reverting the progression to CKD and to more advanced stages [19,22-24]. There is evidence that antiretroviral therapy (ART) can have a positive impact in renal injury caused by HIV, as demonstrated by studies comparing patients continuously exposed to ART against those with intermittent therapy [22,25]. Unfortunately, there is almost no reference regarding mild renal impairment, which is the beginning of renal dysfunction.

The diagnosis of mild renal decline is challenging, as it is silent and only detectable through laboratory analyses. The former equations, Cockcroft-Gault (CG) and modified diet in renal disease (MDRD) only accurately estimate renal function in individuals already with CKD [26-28]. With the validation of chronic kidney disease epidemiology collaboration (CKD-epi) equation for general population, it became more accurate to estimate glomerular filtration rate (eGFR) in individuals with normal or mild impairment of renal function $[19,27,28]$.

Therefore, the objective of our study was to determine the prevalence of mild renal glomerular filtrated rate decline and its associated risk factors in a cohort of well-controlled HIV infected individuals on ART not severely immunosuppressed (CD4 count $>200$ cells $/ \mathrm{mm}^{3}$ ) and with undetectable viral load in Brazil.

\section{Materials and Methods}

\section{Population}

Patients attended in the HIV/AIDS outpatient clinic at Hospital de

*Corresponding author: Eduardo Sprinz, Serviço de Infectologia - Hospital de Clínicas de Porto Alegre Rua Ramiro Barcelos, 2350, sala 700. Porto Alegre, RS, Brasil, Tel: 55-51-3359-8011; Fax: 55-51-3359-8010; E-mail: eduardo.sprinz@gmail.com.br

Received June 22, 2014; Accepted September 07, 2015; Published September 14,2015

Citation: Menezes AM, Torelly J, Barbi C, Camargo CC, Moraes RP, et al. (2015) Mild Decrease in Renal Function in HIV-Infected Patients on Antiretroviral Therapy: A Neglected Diagnosis. J AIDS Clin Res 6: 501. doi:10.4172/2155-6113.1000501

Copyright: (C) 2015 Menezes AM, et al. This is an open-access article distributed under the terms of the Creative Commons Attribution License, which permits unrestricted use, distribution, and reproduction in any medium, provided the original author and source are credited. 
Clínicas (SoBrHIV cohort), Porto Alegre, Brazil, were consecutively enrolled from March, 2009 through September, 2009. The SoBrHIV cohort has already been described elsewhere [29]. Briefly, it is consisted of HIV individuals followed at the southernmost state of Brazil and by the time of the study there was enrolled about 2,500 individuals being followed-up. To be included, patients needed to be on ART and to have undetectable viral load (less than 50 copies $/ \mathrm{mL}$ ) for a period equal or greater than 12 months, CD4 counts higher than 200 cells $/ \mathrm{mm}^{3}$ and age between 18 and 70 years. CKD (eGFR $<60 \mathrm{~mL} / \mathrm{min}$ or with proteinuria) or previous diagnosis of any kidney disease, pregnancy and hepatic insufficiency were exclusion criteria.

\section{Methods}

Data was collected at the moment of the appointment and included demographic variables (ethnicity, height, weight, BMI, sex and age); diagnosis of DM (according to "The American Diabetes Association" [30]), hypertension (according to the Joint National Comittee 7 [31]); a complete history of HIV treatment; use of drugs for prophylaxis against opportunistic infections; the most recent and nadir CD4 cell counts (cells $/ \mathrm{mm}^{3}$, measured by flow cytometry); plasma HIV-RNA level (copies/mL, measured by b-DNA; HIV-1 RNA 3.0 assay, with limit of detection of 50 copies $/ \mathrm{mL})$; serum creatinine $(\mathrm{mg} / \mathrm{dL}$, measured by Jaffé; calibrated method by isotope dilution mass spectrometry IDMS); date of HIV diagnosis and other comorbidities.

Two measurements of CKD-epi and MDRD equations (collected at least three months apart) were performed to determine the eGFR. Mild decrease in renal function was defined as an eGFR between 60 $89 \mathrm{~mL} / \mathrm{min} / 1.73 \mathrm{~m}^{2}$, for a period of at least 3 months. Renal function was further classified in two stages depending on the level of the eGFR: normal $\left(\geq 90 \mathrm{~mL} / \mathrm{min}\right.$ per $\left.1.73 \mathrm{~m}^{2}\right)$ or mild decrease (between $60-89$ $\mathrm{mL} / \mathrm{min}$ per $1.73 \mathrm{~m}^{2}$ ) [32].

The study was approved by the Research and Ethic Committee of Hospital de Clinicas and all patients signed the informed consent.

\section{Statistical analysis}

Statistical analysis included descriptive (mean and standard deviation), univariate and multivariate analysis. Absolute and relative frequencies were utilized for continuous and categorical variables respectively.

Poisson Regression was used to determine the factors associated with mild decrease in renal function in the multivariate model. Variables significantly associated with renal impairment in univariate analysis $(\mathrm{p}<0.05)$ were included in the multivariate model. Pearson coefficient and Bland-Altman graph were used to evaluate the correlation and the concordance between the two equations to eGFR (MDRD and CKDepi). A p value of less than 0.05 was considered significant. Analysis was performed using the statistical package for the social sciences (SPSS) program, version 17.0 (SPSS Inc., Chicago, Illinois, USA).

\section{Sample size}

The sample size calculation was based on a prevalence of $30 \%$ of mild decrease in renal function in the cohort studied with a confidence level of $95 \%$. A sample size of at least 163 individuals was calculated to have a power of $80 \%$.

\section{Results}

From the initial 213 included patients, there were 20 losses (9.4\%): 18 , due to missing laboratory data; one lost to follow-up; and one additional patient died after signing the consent. The characteristics and clinical variables of the remained 193 patients are shown in Table 1. One hundred and two patients were men (52.6\%), 156 were eurodescendants (80.4\%), and the mean age was $41.5 \pm 8.3$ years. Body Mass Index (BMI)was $25.9 \pm 3.99$; mean time on ART was $5.8 \pm 3.7$ years, mean CD4+ count was $585 \pm 179$ cells $/ \mathrm{mm}^{3}$, and the mean nadir CD4 count was $161 \pm 142 \mathrm{cells} / \mathrm{mm}^{3}$. The prevalence of hypertension and Diabetes Mellitus (DM) was 7.2\% $(n=14)$ and $6.2 \%(n=12)$, respectively.

We found that $33.5 \%(n=64)$ patients presented mild decrease in eGFR. The factors significantly associated in the univariate model and further used in the multivariate analysis were every other year of life, being euro-descendant, tenofovir (TDF) exposure, hypertension, DM, time on ART and body weight. After adjustment in the multivariate model (Table 2), every other year of age $(\mathrm{RR}=1.05,95 \% \mathrm{CI} 1.03-1.06$, $<0.001)$ and being euro-descendant $(\mathrm{RR}=1.9495 \% \mathrm{CI} 1.07-3.78, \mathrm{p}=$ 0.049 ) were significantly associated to mild renal decrease in filtration rate. On the other hand, high $\mathrm{BMI}(\mathrm{RR}=1.04,95 \% \mathrm{Cl} 1.013-1.007$, $\mathrm{p}<0.001)$ was a protection factor against renal impairment.

There was a significant correlation between the CKD-epi and MDRD equations (Pearson coefficient $=0.92 ; \mathrm{p}<0.001$ ), although there

\begin{tabular}{|c|c|}
\hline & $\mathrm{N}=193(\%)$ \\
\hline Age (years) & $41.5 \pm 8.3$ \\
\hline Men & $102(52.6 \%)$ \\
\hline \multicolumn{2}{|l|}{ Ethnicity } \\
\hline Euro-descendants & $156(80.4 \%)$ \\
\hline Creatinine (mg/dl) & $0.87 \pm 0.29$ \\
\hline Urea (mg/dl) & $33.51 \pm 12.27$ \\
\hline eGFR* $(\mathrm{ml} / \mathrm{min})$ & $99.02 \pm 29.5$ \\
\hline Body Mass Index & $25.9 \pm 3.99$ \\
\hline CD4 (cells $/ \mathrm{mm}^{3}$ & $585.9 \pm 179.4$ \\
\hline Hypertension & $14(7.2 \%)$ \\
\hline Diabetes Mellitus & $12(6.2 \%)$ \\
\hline Time on $\mathrm{ART}^{\dagger}$ (years) & $5.8 \pm 3.7$ \\
\hline
\end{tabular}

* Estimated glomerular filtration rate; † Antiretroviral therapy

Table 1. Main demographic characteristics (data are presented as mean \pm standard deviation or percentage).

\begin{tabular}{|l|c|c|c|c|c|c|}
\hline & \multicolumn{3}{|c|}{ Univariate analysis } & \multicolumn{2}{c|}{ Multivariate analysis } \\
\hline & $R R$ & $95 \% \mathrm{Cl}^{\dagger}$ & $p$ & $\mathrm{RR}^{\ddagger}$ & $95 \% \mathrm{Cl}$ & $p$ \\
\hline Euro-descendants & $\mathbf{2 . 9 4 2}$ & $\mathbf{1 . 1 3 - 7 . 6 5}$ & $\mathbf{0 . 0 2 7}$ & $\mathbf{1 . 9 4 1}$ & $\mathbf{1 . 0 7 - 3 . 7 8}$ & $\mathbf{0 . 0 4 9}$ \\
\hline Men & 0.728 & $0.45-1.13$ & 0.192 & & & \\
\hline Use of atazanavir & 1.129 & $0.66-1.91$ & 0.654 & & & \\
\hline Use of tenofovir & 1.847 & $1.16-2.95$ & 0.009 & 1.344 & $0.97-1.85$ & 0.07 \\
\hline Use of ritonavir (100mg) & 0.915 & $0.49-1.71$ & 0.781 & & & \\
\hline Use of ritonavir (200mg) & 0.728 & $0.37-1.43$ & 0.357 & & & \\
\hline Hypertension & 2.444 & $1.57-3.78$ & $<0.001$ & 1.170 & $0.789-$ & 0.44 \\
\hline Diabetes Mellitus & 2.347 & $1.48-3.71$ & $<0.001$ & 0.874 & $0.58-1.30$ & 0.5 \\
\hline Every other year of life & 1.066 & $\mathbf{1 . 0 5 - 1 . 0 8}$ & $<\mathbf{0 . 0 0 1}$ & $\mathbf{1 . 0 5 1}$ & $\mathbf{1 . 0 3 4 -}$ & $<0.001$ \\
\hline Time on ART (years) & 1.054 & $1.006-1.104$ & 0.026 & 1.012 & $0.97-1.05$ & 0.505 \\
\hline Body Mass Index & $\mathbf{1 . 0 5 5}$ & $\mathbf{1 . 0 1 8 - 1 . 0 2 1}$ & $\mathbf{0 . 0 0 4}$ & $\mathbf{1 . 0 4}$ & $\mathbf{1 . 0 1 3 -}$ & $<\mathbf{0 . 0 0 1}$ \\
\hline CD4 (cells/mm ${ }^{3}$ ) & 1.00 & $1.00-1.001$ & 0.661 & & 1.007 & \\
\hline
\end{tabular}

* eGFR, estimated glomerular filtration rate; $† \mathrm{Cl}$, confidence interval; $\ddagger \mathrm{RR}$, risk ratio; All variables significant in univariate analyses $(p<0.05)$ were included in a multivariate model.

Table 2.Risk factors associated to alteration in the renal function (eGFR * $<60 \mathrm{ml}$ minper $1.73 \mathrm{~m}^{2}$ by CKD-epi); univariate and multivariate analysis. 
were no concordance between the CKD-epi and MDRD equations (Bland-Altman graph analysis $\mathrm{p}=0.048 ; 95 \%$ IC $-19.36 \pm 22.34$ ).

\section{Discussion}

In our study we evaluated mild renal impairment and its associated factors in a well-controlled HIV population $(<50$ copies $/ \mathrm{mL}$ and $>200$ $\mathrm{CD} 4+$ cells $/ \mathrm{mm}^{3}$ for at least one year). To our knowledge this is the first study that looked for early renal disease in controlled HIV population without previous known kidney disease. We found an extremely high and worrisome prevalence of $33.5 \%$ of mild dysfunction by eGFR, which merits further attention to this particular organ as a potential target in HIV infection. This finding is in accordance to study conducted in a different HIV cohort from France, although only about $60 \%$ of the individuals had undetectable viral load [14]. Another cohort (ICONA) found a prevalence of almost $24 \%$ of mild renal glomerular decline. Nevertheless, in this population HIV disease was not well-controlled [33].

This finding supports the kidney as a frequent target even in wellcontrolled HIV infection and is in accordance to the other studies $[14,33]$. Moreover, the mean age of our cohort was only 41.5 year of age and such alterations should be noticed in older individuals in the general population [19,34]. Likely, this also might reflect the process of early ageing being suggested in HIV infection as reported with other organs and tissues of the body $[2,3,18,35]$. Therefore, we could speculate that the beginning of renal disease would be earlier than expected in this particular group.

Among the traditional risk factors only age was significantly associated to mild decrease of eGFR, although being euro-descendant was also significantly associated to mild renal disease. Other well known risk factors for renal impairment, like hypertension and DM $[8,36]$, were not associated after adjustment in the multivariate model. This could be due to the not large enough sample size of our study, as the prevalence of hypertension and DM was lower than expected $(7.2 \%$ and $6.2 \%$ respectively) in contrast to $10 \%$ in DM and approximately $20 \%$ of hypertension among Brazilian adults [37-39]. The lower prevalence of both conditions was somewhat expected due to the relative youthness of our population.

Surprisingly, we found an association between ethnicity and mild decrease of eGFR. Previous studies, looking to chronic kidney disease $(e G F R<60 \mathrm{~mL} / \mathrm{min})$ did not identify any association between renal impairment with euro-descendant individuals $[7,12,40]$. In our population, utilizing afro-descendant as the comparator, those with an European ancestry were at risk for mild renal decrease. A possible explanation would reside in the fact that the equations used nowadays to eGFR were based according to other populations that not necessarily resembled the ethnic distribution of our cohort.

On the other hand, no specific antiretroviral or time on antiretroviral agents, which had been previously associated to CKD in our population, were associated to mild lost in renal eGFR [4-8,1215]. This finding should be further explored since it could be related to the differences in age of the selected populations. For instance, in the CKD study [15], the mean age was 46 years opposed to 41.5 years in the present study. Therefore, although risky, it is possible to consider that this could reflect a continuum, in which renal disease progresses with antiretroviral exposition. Conversely, this could simply mirror the chronic inflammatory milieu associated to HIV infection and ageing $[2,35]$.
Another intriguing finding was related to the BMI, which was significantly related to renal protection. Individuals with higher BMI were associated to normal eGFR. It is difficult to try to interpret the result as the equations utilized to eGFR (MDRD and CKD-epi) do not take in account body weight in their composition. In that circumstance, as the drugs are prescribed in fixed dosage for adults, individuals with higher body weight would have lower plasma concentrations to these drugs and consequently last exposure, as clearly demonstrated by efavirenz, for example [41]. Nevertheless, if we consider renal disease as a continuum, it would reflect that some antiretrovirals, in fact, could really be nephrotoxic $[4,7,16,42-44]$. Likewise for antiretroviral exposition, this would only reveal the continuum spectrum of renal disease in HIV infection, in which individuals with lower weight (meaning hypercatabolic despite well controlled disease) might have a more pro-inflammatory profile associated to greater risk of organ disease [19].

The study has several limitations that should be considered. The equations used to eGFR are still not validated to HIV-infected individuals and therefore could be not accurate enough. As previously considered, our sample size might have been limited some of our findings, as the prevalence of chronic diseases such as hypertension and DM were lower than expected. In addition, this was a cross sectional study and therefore we can only draw association of events and not establish temporal sequence. Lastly, although we tried to minimize HIV infection and its comorbidities selecting individuals with CD4 counts greater than 200 cells $/ \mathrm{mm}^{3}$ and at least one year with undetectable viral load, it is not possible to exclude any influence of HIV infection.

In conclusion, we have demonstrated that mild decrease in renal function is relatively common in our population. According to our findings, those with older age, euro-descendant and with low body weight were at higher risk to have mild decrease in renal function. We suggest that kidney disease begins earlier than expected and it is a continuum (despite adequately viral suppression) and it should be taken along with the process of ageing in HIV population.

Actually, due to the increase of life-expectancy of HIV individuals, we can expect an even higher prevalence of renal disease. Therefore it is very important to screen and aggressively treat mild renal impairment. Other prospective studies should confirm our findings [22,45].

\section{Competing Interests}

We certify that there is no competing interest regarding the material discussed in the manuscript.

\section{Acknowledgements}

This work was supported by Fundo de incentivo a Pesquisa do Hospital de Clínicas de Porto Alegre (FIPE), CAPES/REUNI and CNPq.

\section{References}

1. Palella FJ Jr, Baker RK, Moorman AC, Chmiel JS, Wood KC, et al. (2006) Mortality in the highly active antiretroviral therapy era: changing causes of death and disease in the HIV outpatient study. J Acquir Immune Defic Syndr 43: 27-34.

2. Capeau J (2011) Premature Aging and Premature Age-Related Comorbidities in HIV-Infected Patients: Facts and Hypotheses. Clin Infect Dis 53: 1127-1129.

3. Burgess MJ, Kasten MJ (2013) Human immunodeficiency virus: what primary care clinicians need to know. Mayo Clin Proc 88: 1468-1474.

4. Wyatt CM, Klotman PE (2006) Antiretroviral therapy and the kidney: balancing benefit and risk in patients with HIV infection. Expert Opin Drug Saf 5: 275-287.

5. Ray PE (2012) HIV-associated nephropathy: a diagnosis in evolution. Nephrol Dial Transplant 27: 3969-3972. 
Citation: Menezes AM, Torelly J, Barbi C, Camargo CC, Moraes RP, et al. (2015) Mild Decrease in Renal Function in HIV-Infected Patients on Antiretroviral Therapy: A Neglected Diagnosis. J AIDS Clin Res 6: 501. doi:10.4172/2155-6113.1000501

Page 4 of 4

6. Mocroft A, Kirk O, Gatell J, Reiss P, Gargalianos P, et al. (2007) Chronic renal failure among HIV-1-infected patients. AIDS 21: 1119-1127.

7. Mocroft A, Kirk O, Reiss P, De Wit S, Sedlacek D, et al. (2010) Estimated glomerular filtration rate, chronic kidney disease and antiretroviral drug use in HIV-positive patients. AIDS 24: 1667-1678.

8. Morlat P, Vivot A, Vandenhende MA, Dauchy FA, Asselineau J, et al. (2013) Role of traditional risk factors and antiretroviral drugs in the incidence of chronic kidney disease, ANRS CO3 Aquitaine cohort, France, 2004-2012. PLoS One 8: e66223.

9. Gupta SK, Eustace JA, Winston JA, Dauchy FA, Asselineau J, et al. (2005) Guidelines for the management of chronic kidney disease in HIV-infected patients: recommendations of the HIV Medicine Association of the Infectious Diseases Society of America. Clin Infect Dis 40: 1559-1585.

10. Izzedine H, Launay-Vacher V, Deray G (2005) Antiviral drug-induced nephrotoxicity. Am J Kidney Dis 45: 804-817.

11. Calza L, Vanino E, Magistrelli E, Salvadori C, Cascavilla A, et al. (2014) Prevalence of renal disease within an urban HIV-infected cohort in northern Italy. Clin Exp Nephrol 18: 104-112.

12. Crum-Cianflone N, Ganesan A, Teneza-Mora N, Riddle M, Medina S, et al. (2010) Prevalence and factors associated with renal dysfunction among HIVinfected patients. AIDS Patient Care STDS 24: 353-360.

13. Ryom L, Mocroft A, Kirk O, Ross M, Reiss P, et al. (2014) Predictors of advanced chronic kidney disease and end-stage renal disease in HIV-positive persons. AIDS 28: 187-199.

14. Déti EK, Thiébaut R, Bonnet F, Lawson-Ayayi S, Dupon M, et al. (2010) Prevalence and factors associated with renal impairment in HIV-infected patients, ANRS C03 Aquitaine Cohort, France. HIV Med 11: 308-317.

15. Menezes AM, Torelly J Jr, Real L, Bay M, Poeta J, et al. (2011) Prevalence and risk factors associated to chronic kidney disease in HIV-infected patients on HAART and undetectable viral load in Brazil. PLoS One 6: e26042.

16. Phair J, Palella F (2011) Renal disease in HIV-infected individuals. Curr Opin HIV AIDS 6: 285-289.

17. Lucas GM, Cozzi-Lepri A, Wyatt CM, Post FA, Bormann AM, et al. (2014) Glomerular filtration rate estimated using creatinine, cystatin $C$ or both markers and the risk of clinical events in HIV-infected individuals. HIV Med 15: 116-123.

18. Deeks SG, Tracy R, Douek DC (2013) Systemic effects of inflammation on health during chronic HIV infection. Immunity 39: 633-645.

19. Levey AS, Coresh J (2012) Chronic kidney disease. Lancet 379: 165-180.

20. Campbell LJ, Desai M, Hegazi A, Ibrahim F, Melikian N, et al. (2012) Rena impairment is associated with coronary heart disease in HIV-positive men. HIV Clin Trials 13: 343-349.

21. Phillips AN, Neaton J, Lundgren JD (2008) The role of HIV in serious diseases other than AIDS. AIDS 22: 2409-2418.

22. Schwartz EJ, Szczech LA, Ross MJ, Klotman ME, Winston JA, et al. (2005) Highly active antiretroviral therapy and the epidemic of HIV+ end-stage renal disease. J Am Soc Nephrol 16: 2412-2420.

23. Izzedine H, Baumelou A, Deray G (2007) Acute renal failure in HIV patients. Nephrol Dial Transplant 22: 2757-2762.

24. Beddhu S, Samore MH, Roberts MS, Stoddard GJ, Ramkumar N, et al. (2003) Impact of timing of initiation of dialysis on mortality. J Am Soc Nephrol 14: 2305-2312.

25. Ryom L, Mocroft A, Lundgren J (2012) HIV therapies and the kidney: some good, some not so good? Curr HIVIAIDS Rep 9: 111-120.

26. Levey AS, Bosch JP, Lewis JB, Greene T, Rogers N, et al. (1999) A more accurate method to estimate glomerular filtration rate from serum creatinine: a new prediction equation. Modification of Diet in Renal Disease Study Group. Ann Intern Med 130: 461-470.

27. Skali H, Uno H, Levey AS, Inker LA, Pfeffer MA, et al. (2011) Prognostic assessment of estimated glomerular filtration rate by the new Chronic Kidney Disease Epidemiology Collaboration equation in comparison with the Modification of Diet in Renal Disease Study equation. Am Heart J 162: 548-554.

28. Soares AA, Eyff TF, Campani RB, Ritter L, Weinert LS, et al. (2010) Performance of the CKD Epidemiology Collaboration (CKD-EPI) and the Modification of Diet in Renal Disease (MDRD) Study equations in healthy South Brazilians. Am J Kidney Dis 55: 1162-1163.

29. Dabis F, Balestre E, Braitstein P, Miotti P, Brinkhof WG, et al. (2005) Cohor Profile: Antiretroviral Therapy in Lower Income Countries (ART-LINC) international collaboration of treatment cohorts. Int J Epidemiol 34: 979-986.

30. American Diabetes Association (2010) Diagnosis and classification of diabetes mellitus. Diabetes Care 33: S62-S69.

31. Chobanian AV, Bakris GL, Black HR, Cushman WC, Green LA, et al. (2003) The Seventh Report of the Joint National Committee on Prevention, Detection, Evaluation, and Treatment of High Blood Pressure: the JNC 7 report. JAMA 289: $2560-2572$

32. National Kidney Foundation (2002) K/DOQI clinical practice guidelines for chronic kidney disease: evaluation, classification, and stratification. Am J Kidney Dis 39: S1-266.

33. Tordato F, Cozzi Lepri A, Cicconi P, De Luca A, Antinori A, et al. (2011) Evaluation of glomerular filtration rate in HIV-1-infected patients before and after combined antiretroviral therapy exposure. HIV Med 12: 4-13.

34. Otani H, Mune M (1998) Kidney disease in aging. Age (Omaha) 21: 105-108.

35. Guaraldi G, Orlando G, Zona S, Menozzi M, Carli F, et al. (2011) Premature age-related comorbidities among HIV-infected persons compared with the general population. Clin Infect Dis 53: 1120-1126.

36. Hsieh MH, Lu PL, Kuo MC, Lin WR, Lin CY, et al. (2015) Prevalence of and associated factors with chronic kidney disease in human immunodeficiency virus-infected patients in Taiwan. J Microbiol Immunol Infect 48: 256-262.

37. Goldenberg P, Schenkman S, Franco LJ (2003) Prevalence of diabetes mellitus: gender differences and sex equalityes. Rev Bras Epidemiol 6:14-18.

38. Torquato MT, Montenegro Júnior RM, Viana LA, de Souza RA, Lanna CM, et al. (2003) Prevalence of diabetes mellitus and impaired glucose tolerance in the urban population aged 30-69 years in RibeirãoPreto (São Paulo), Brazil. Sao Paulo Med J 121: 224-230.

39. Passos AV, Assis TD, Barreto SM (2006) Hypertension in Brazil: Estimates from Population-Based Prevalence Studies. Epidemiologia e Serviços de Saúde 15: 35-45.

40. Mocroft A, Ryom L, Begovac J, Monforte AD, Vassilenko A, et al. (2014) Deteriorating renal function and clinical outcomes in HIV-positive persons. AIDS 28: 727-737.

41. Poeta J, Linden R, Antunes MV, Real L, Menezes AM, et al. (2011) Plasma concentrations of efavirenz are associated with body weight in HIV-positive individuals. J Antimicrob Chemother 66: 2601-2604.

42. Calza L (2012) Renal toxicity associated with antiretroviral therapy. HIV Clin Trials 13: 189-211.

43. Kalyesubula R, Perazella MA (2011) Nephrotoxicity of HAART. AIDS Res Treat 2011: 562790 .

44. Brennan A, Evans D, Maskew M, Naicker S, Ive P, et al. (2011) Relationship between renal dysfunction, nephrotoxicity and death among HIV adults on tenofovir. AIDS 25: 1603-1609.

45. Lima VD, Hogg RS, Harrigan PR, Moore D, Yip B, et al. (2007) Continued improvement in survival among HIV-infected individuals with newer forms of highly active antiretroviral therapy. AIDS 21: 685-692. 